\section{Joiner v. General Electric (1997)}

Robert L. Heilbronner

Chicago Neuropsychology Group, Chicago, IL, USA

\section{Definition}

The Daubert criteria (Daubert v. Merrell Dow for more detail) was further revised in the cases of Joiner v. General Electric (1997) and Kumho Tire v. Carmichael (1999). While the Daubert and Kumho decisions dealt exclusively with methodological bases underlying an opinion, the Supreme Court used the Joiner v. General Electric decision to further expand the gatekeeper role of the judge to include admissibility of expert's conclusions. Specifically, in Joiner, a trial judge prohibited an expert witnesses' testimony claiming that lung cancer was caused by PCB exposure because the expert's process of deduction relied on irrelevant epidemiological and animal studies. The studies cited very different circumstances from the case at hand and in the animal studies involved much higher doses of PCB exposure. The Joiner court ruled that it was within a trial court's discretion to disqualify opinion evidence based on no more than the fact the expert said it (ipse dixit), irrespective if the extrapolated-form studies were themselves scientifically sound and reliable. Any extrapolation from literature to individual legal cases has to be bridged by links other than the expert's belief that there is a link. In neuropsychology, this could mean that introduction of valid and replicated neuropsychological principles could still be barred if not generalizable. As an example, Grieffenstein (2008) points out that the General Neuropsychological Deficit Scale may be sensitive to metastasized brain cancer, but that does not automatically mean that it is generalizable to remote mild head trauma cases.

\section{Cross-References}

- Admissibility

- Daubert v. Merrell Dow

- Kumho Tire v. Carmichael

\section{References and Readings}

Daubert v. Merrell Dow, 509 U.S. 579 (1993).

Frye v. United States, (1923).

Greiffenstein, M. F. (2009). Basics of forensic neuropsychology. In J. Morgan \& J. Ricker (Eds.), Textbook of clinical neuropsychology. New York: Psychology Press.

Joiner v. General Electric, 522 U.S., 136 (1997).

Kumho v. Carmichael, 526 U.S., 137 (1999). 